\title{
Práticas maternas frente aos problemas de saúde do recém-nascido no primeiro mês de vida
}

\author{
Maternal practices face to newborn health problems in the first month of life \\ Prácticas maternas frente a los problemas de la salud del niño en el primer mes de vida \\ Kamila Caroline Minosso ${ }^{1}$ (D) https://orcid.org/0000-0001-5451-8356 \\ Beatriz Rosana Gonçalves de Oliveira Tos0 ${ }^{1}$ (D) https://orcid.org/0000-0001-7366-077x \\ Maria Aparecida Baggio ${ }^{1}$ (D) https://orcid.org/0000-0001-6901-461x \\ Rosângela Aparecida Pimenta Ferrari² ${ }^{2}$ https://orcid.org/0000-0003-0157-7461
}

\section{Resumo}

Objetivo: Identificar as práticas maternas frente aos problemas de saúde mais comuns do recém-nascido, no primeiro mês de vida.

Métodos: Estudo quantitativo, exploratório, transversal, integrante de pesquisa multicêntrica, realizado em 2018, por meio de entrevista com 52 mulheres no puerpério, em município do Oeste do Paraná, cuja análise de dados foi a estatística descritiva.

Resultados: As puérperas foram orientadas sobre os cuidados com o bebê pela equipe de saúde da maternidade $(86,5 \%)$ e nas consultas de puericultura $(83,7 \%)$. Os problemas recorrentes foram cólicas $(40,4 \%)$, dermatites $(40,4 \%)$ e febre $(7,7 \%)$. Entre as puérperas, $33,3 \%$ usaram medicamentos caseiros no banho para tratar a dermatite e $25,0 \%$ afirmaram oferecer chás ao bebê.

Conclusão: As puérperas são orientadas pelos profissionais de saúde no pós-parto e nas consultas de puericultura quanto aos cuidados com o recém-nascido, todavia, nota-se que persistem os cuidados maternos baseados em crenças influenciadas pelo contexto familiar e social.

\section{Abstract}

Objective: To identify maternal practices in relation to the newborn more common health problems, in the first month of life.

Methods: Quantitative, exploratory, transversal study, integrating of a multicenter researcher, occurred in 2018, though interviews with 52 puerperae, in a municipality in the west of Paraná, with descriptive statistical data analysis.

Results: The puerperae were instructed on the care of the baby by the maternity health team $(86.5 \%)$ and in childcare consultations $(83.7 \%)$. The recurrent problems were colic $(40.4 \%)$, dermatitis $(40.4 \%)$ and fever $(7.7 \%)$. Among the puerperal women, $33.3 \%$ used homemade medicines in the bath to treat dermatitis and $25.0 \%$ said they offered teas to the baby.

Conclusion: Postpartum women are advised by postpartum health professionals and in childcare consultations regarding newborn care. However, maternal care based on beliefs influenced by the family and social context persists.

\section{Resumen}

Objetivo: Identificar las prácticas maternas frente a los problemas de salud más comunes del recién-nacido, en el primer mes de vida.

Métodos: Estudio cuantitativo, exploratorio, trasversal, integrante de investigación multicéntrica, realizado en 2018 , por medio de entrevista con 52 mujeres en el puerperio, en municipio del Oeste de Paraná, con análisis de datos estadísticos descriptivos.

Resultados: Las puérperas fueron orientadas sobre los cuidados con el bebé por el equipo de salud de la maternidad $(86,5 \%)$ y en las consultas de puericultura $(83,7 \%)$. Los problemas recurrentes fueron cólicos $(40,4 \%)$, dermatitis $(40,4 \%)$ y fiebre $(7,7 \%)$. Entre las puérperas, el $33,3 \%$ usaron medicamentos caseros en el baño para tratar la dermatitis y el $25,0 \%$ afirmó ofrecer té al bebé.

Conclusión: Las puérperas son orientadas por los profesionales de salud en el posparto y en las consultas de puericultura en cuanto a los cuidados con el recién nacido, sin embargo, se observa que persisten los cuidados maternos basados en creencias influenciadas por el contexto familiar y social.

\section{Descritores}

Enfermagem Pediátrica; Recém-nascido;

Saúde materno-infantil; Cuidado da criança

\section{Keywords}

Pediatric Nursing; Newborn; Maternal and child health; Child care

\section{Descriptores}

Enfermería Pediátrica; Recién Nacido; Salud materno-infatil; Cuidado del niño

\section{Como citar:}

Minosso KC, Toso BR, Baggio MA, Ferrari RA. [Maternal practices face to newborn health problems in the first month of life]. Rev Soc Bras Enferm Ped. 2019;19(1):32-8. Portuguese

\footnotetext{
Universidade Estadual do Oeste do Paraná, Cascavel, Paraná, Brasil.

${ }^{2}$ Universidade Estadual de Londrina, Londrina, Paraná, Brasil.

Conflitos de interesse: nada a declarar.

Submetido: 29 de Março de 2019 | Aceito: 28 de Junho de 2019

Autor correspondente: Beatriz Rosana Gonçalves de Oliveira Toso | E-mail: Ib.toso@gmail.com

DOI: http://dx.doi.org/10.31508/1676-3793201900005
} 


\section{Introdução}

A partir do parto, o Recém-Nascido ( $\mathrm{RN}$ ) requer daqueles em seu entorno, cuidados específicos como a manutenção da temperatura, a posição para permanecer na cama, a alimentação, a higiene e, especialmente, os afetivos, de proteção, amor, carinho e abrigo. Assim, o nascimento traz consigo a necessidade do exercício da parentalidade, ou seja, assumir as responsabilidades inerentes ao cuidado do bebê. ${ }^{(1)}$

O RN é vulnerável por sua condição de dependência total dos cuidados advindos dos adultos, e tais ações exigem responsabilidade e dedicação, devido à sua complexidade. Nesse cenário, os enfermeiros desempenham um papel relevante no aprimoramento de intervenções sensíveis às necessidades e que, ao mesmo tempo, favoreçam o empoderamento das mulheres e de suas famílias, otimizando as trajetórias de desenvolvimento das crianças, com ações que iniciam no pré-natal, passam pelas maternidades, pelo puerpério e prosseguem na puericultura. ${ }^{(2)}$

A orientação de cuidados com o RN estará dentre as práticas do enfermeiro em todos os espaços mencionados. Destarte, mesmo que o aconselhamento das mulheres sobre o cuidado com o bebê seja efetivo, poderá ocorrer situações em que estas não saberão como lidar com os problemas mais comuns no primeiro mês de vida, período considerado de adaptação pelo qual passam as famílias em sua nova constituição. ${ }^{(2)}$ Portanto, orientar os pais e os familiares é fundamental, capacitando-os a se envolverem no processo saúde-doença e empoderando-os do saber para cuidar de seus bebês. ${ }^{(3)}$

Ademais, a enfermagem possui papel fundamental na construção do vínculo familiar com o RN, para além do cuidado cotidiano com rotinas e protocolos de atenção. É consenso que a presença da família é imprescindível no processo de adaptação pós-parto e também quanto aos benefícios de seu suporte na instituição hospitalar e em casa. Para tanto, a equipe de enfermagem necessita inserir os familiares nos cuidados durante a hospitalização de forma planejada e gradativa, oferecendo tempo necessário para adaptar-se às novas rotinas. ${ }^{(4)}$

Vale ressaltar que nesta fase de adaptação, as ações de cuidado também sofrem influência de práticas que pretendem oferecer proteção ao binômio mãe-bebê. É um momento no qual a mulher é confrontada com crenças, valores e mitos herdados de forma intergeracional e de seu meio sociocultural, sobre os cuidados com o bebê e, principalmente, o aleitamento materno. ${ }^{(5)}$

Ainda, estudo qualitativo aponta que as principais dificuldades encontradas no cuidado com o RN, estão relacionadas à higiene e conforto do bebê, amamentação, cuidados com o coto umbilical, manutenção da temperatura, estratégias para melhorar o quadro de cólica e segurança. ${ }^{(2)}$

No âmbito de iniciativas criadas pelo governo com o intuito de melhorar a saúde dessa população, em 2015, o Ministério da Saúde instituiu a Política Nacional de Atenção Integral à Saúde da Criança (PNAISC), com o objetivo de promover e proteger a saúde da criança e o aleitamento materno, mediante a atenção e cuidados integrais e integrados da gestação aos nove anos de vida. ${ }^{(6)}$

Tais esforços são necessários para reduzir o índice de mortalidade infantil e materna, além de promover a qualidade de vida dessa população. ${ }^{(7)}$ Contudo, as mães primíparas, precisam de atenção especial porque podem apresentar falta de conhecimento e experiência para lidar com o filho. ${ }^{(2)}$ Assim, acredita-se que, quando a mãe é orientada sobre como cuidar do RN, saberá lidar melhor com os problemas de saúde e necessitará com menor frequência do suporte das unidades de saúde com o filho doente e, consequentemente, influenciará na redução dos índices de morbimortalidade infantil.

Face ao exposto, objetivou-se nesse estudo identificar as práticas maternas frente aos problemas de saúde mais comuns do recém-nascido, no primeiro mês de vida.

\section{Métodos}

O presente estudo compõe a pesquisa multicêntrica de avaliação do programa Rede Mãe Paranaense, denominada "Rede Mãe Paranaense na perspectiva da usuária: o cuidado da mulher no pré-natal, parto, puerpério e da criança". Trata-se de um estudo utilizando abordagem quantitativa, de caráter transversal e de delineamento exploratório, do qual participam a Universidade Estadual de Londrina - UEL e a Univer- 
sidade Estadual do Oeste do Paraná - Unioeste. O estudo foi aprovado pelo Comitê de Ética em Pesquisa, sob parecer $\mathrm{n}^{\mathrm{o}}$ 2.053.304. Em todas as etapas garantiu-se o anonimato aos participantes e os mesmos assinaram o Termo de Consentimento Livre e Esclarecido - TCLE, dando ciência de sua participação voluntária na pesquisa.

A coleta de dados para a primeira etapa do projeto multicêntrico ocorreu com puérperas, em três maternidades nas regiões Oeste e Norte do Paraná. Para este estudo foram utilizadas informações do banco de dados do projeto multicêntrico para contatar puérperas/mães de $\mathrm{RN}$, cujo nascimento ocorreu em maternidade de hospital universitário da região Oeste do Paraná, cuja amostra era de 423 puérperas. Destas, estratificou-se nova amostra para atender ao objetivo deste estudo, num total de 52, que atenderam aos critérios de inclusão: mulheres que realizaram o parto nas maternidades em estudo, que aceitaram participar da pesquisa, que residiam na área urbana do município, bem como não apresentaram nenhum tipo de agravo e/ou problema de saúde que impedisse sua participação.

Foram realizadas entrevistas por telefone com as mães, orientadas por questionário estruturado, cujas variáveis estão descritas nos resultados, aos 30 dias de vida do recém-nascido, no ano de 2017. Os dados foram digitados em planilha do programa Microsoft ${ }^{\circledR}$ Office Excel, versão 2016, por dois digitadores, com dupla conferência. A análise foi estatística descritiva, resultando nas frequências absolutas e relativas.

\section{Resultados}

Na tabela 1 apresentam-se os dados sobre as orientações fornecidas à puérpera no ambiente hospitalar.

A maioria das participantes (98,07\%) recebeu orientação para o retorno à Unidade Básica de Saúde (UBS), destacando-se que $84,62 \%$ foram orientadas para retorno puerperal e do recém-nascido. Diante de qual serviço buscar na ocorrência de complicações com o RN, em 73,08\% dos casos as mulheres foram orientadas, sendo indicado a UBS (42,31\%) e hospital $(30,77 \%)$. O profissional mais reportado como aquele que orientou foi o enfermeiro $(57,69 \%)$. Quanto ao recebimento das imunizações ainda no hospital, todos
Tabela 1. Orientações fornecidas à puérpera na maternidade, quanto ao seguimento na rede básica municipal

\begin{tabular}{lcc}
\hline Orientações para assistência na rede básica & Sim(\%) & Não(\%) \\
\hline $\begin{array}{l}\text { Retorno na UBS até 10 dias - Consulta } \\
\text { Puerperal }\end{array}$ & $4(7,69)$ & $48(92,31)$ \\
$\begin{array}{l}\text { Retorno na UBS Consulta 1 }{ }^{\text {a }} \text { semana de } \\
\text { vida do RN }\end{array}$ & $3(5,77)$ & $49(94,23)$ \\
Retorno mãe e filho na UBS & $44(84,62)$ & $8(15,38)$ \\
Foi orientada para o seguimento na UBS & $51(98,07)$ & $1(1,93)$ \\
Orientado qual serviço buscar para atenção & $38(73,08)$ & $14(26,92)$ \\
à saúde: & & \\
$\quad$-UBS & $22(42,31)$ & $30(57,69)$ \\
$\quad$-UPA & $4(7,69)$ & $48(92,31)$ \\
$\quad$-Hospital & $16(30,77)$ & $36(69,23)$ \\
Profissional que orientou: & & \\
$\quad$-Médico & $4(7,69)$ & $48(92,31)$ \\
$\quad$-Enfermeiro & $30(57,69)$ & $22(42,31)$ \\
$\quad$-Técnico de Enfermagem & $4(7,69)$ & $48(92,31)$ \\
Recebeu imunizações na maternidade & & \\
$\quad$-BCG (Bacilo de Calmette-Guérin) & $52(100,0)$ & - \\
$\quad$-Hepatite B & $52(100,0)$ & - \\
\hline
\end{tabular}

UBS - Unidade Básica de Saúde; RN - Recém-Nascido; UPA - Unidade de Pronto-Atendimento

os RN (100\%) as receberam. Na tabela 2, apresentam-se os dados relativos ao tipo de orientações oferecidas pela equipe de saúde da maternidade quanto aos cuidados com o RN em casa, e da puérpera com sua condição pós-parto.

Tabela 2. Orientações oferecidas pela equipe de saúde da maternidade quanto aos cuidados com o RN em casa e da puérpera

\begin{tabular}{lcc}
\hline Orientações sobre cuidados & Sim(\%) & Não(\%) \\
\hline Recebeu orientação sobre cuidados & $45(86,54)$ & $7(13,46)$ \\
Orientada sobre cuidados com: & & \\
$\quad$-Higiene do bebê & $39(75,0)$ & $13(25,0)$ \\
$\quad$-Coto umbilical & $39(75,0)$ & $13(25,0)$ \\
-Banho de sol se apresentar icterícia & $19(36,54)$ & $33(63,46)$ \\
-Sinais de infecção neonatal & $23(44,23)$ & $29(55,77)$ \\
-Aleitamento Materno Exclusivo (AME) & $39(75,0)$ & $13(25,0)$ \\
-Problemas com as mamas & $15(28,85)$ & $37(71,15)$ \\
-Sono/repouso da mãe e bebê & $13(25,0)$ & $39(75,0)$ \\
-Problemas com incisão cirúrgica ou & $19(36,54)$ & $33(63,46)$ \\
$\quad$ episiotomia & & \\
-Lóquios & $16(30,77)$ & $36(69,23)$ \\
-Manutenção do AME & $51(98,07)$ & $1(1,93)$ \\
Orientada a procurar atendimento se tiver & & \\
dificuldades com AME & $34(65,38)$ & $18(34,52)$ \\
- No banco de leite & $34(65,38)$ & $18(34,52)$ \\
- Em Unidade Básica de Saúde (UBS) & - & $52(100,0)$ \\
- Em outros serviços & - & $52(100,0)$ \\
\hline
\end{tabular}

A maioria das puérperas foi orientada $(86,54 \%)$, principalmente sobre como realizar adequadamente a higiene do bebê (75\%), a importância do aleitamento materno exclusivo $(75 \%)$ e quais os cuidados necessários com o coto umbilical (64\%), apesar de que sete $(13,46 \%)$ reportaram não ter recebido informações so- 
bre os cuidados. Com relação à manutenção do aleitamento materno, foi indicado para a maioria $(65,38 \%)$ que, caso houvesse alguma dificuldade para amamentar, devia-se procurar o banco de leite do hospital. $\mathrm{Na}$ tabela 3 encontram-se os dados relativos à atitude da mãe frente aos problemas de saúde de seu bebê, quanto ao serviço que procura para resolvê-los e se recebeu a visita domiciliar da equipe de saúde até o quinto dia de vida do RN.

Tabela 3. Serviços procurados pela mãe frente aos problemas de saúde de seu filho, visita da equipe de saúde até $05^{\circ}$ dia de vida do RN e agenda de consulta na visita domiciliar

\begin{tabular}{lcc}
\hline Características investigadas & Sim(\%) & Não(\%) \\
\hline Local em que busca atendimento: & & \\
$\quad$-UBS & $50(96,15)$ & $2(3,85)$ \\
-UPA & $2(3,85)$ & $50(96,15)$ \\
$\quad$-Consultório particular & - & $52(100,0)$ \\
$\quad$-Outros & - & $52(100,0)$ \\
Recebeu visita domiciliar até $5^{\circ}$ dia vida RN & $10(19,23)$ & $42(80,77)$ \\
Dias de vida RN agendamento primeira consulta UBS: & & \\
$\quad$-Até 7 dias & $5(9,62)$ & $47(90,38)$ \\
-8 a 15 dias & $39(75,0)$ & $13(25,0)$ \\
-16 a 30 dias & $5(9,62)$ & $47(90,38)$ \\
- Não consultou no primeiro mês & $3(5,77)$ & $49(94,23)$ \\
No Consultas primeiro mês: & & \\
-Uma & $36(69,23)$ & $16(30,77)$ \\
-Duas & $13(25,0)$ & $39(75,0)$ \\
-Três e mais & $2(3,85)$ & $50(96,15)$ \\
\hline
\end{tabular}

No que tange ao serviço que busca quando necessita de atendimento, aponta-se que a maioria das mães procuram a UBS (96,15\%), 19,23\% receberam a visita domiciliar da equipe de saúde, a primeira consulta do $\mathrm{RN}$ foi marcada entre o oitavo e o $15^{\mathrm{o}}$ dia de vida (75\%) e foi realizada uma consulta no primeiro mês para a maioria $(69,23 \%)$. Na tabela 4 apresentam-se os dados relativos à consulta com o $\mathrm{RN}$, referente às características da consulta e orientações oferecidas.

No que se refere à primeira consulta do $\mathrm{RN}$ na UBS, 94,23\% deles compareceram. Em relação aos procedimentos realizados durante a consulta, percebe-se que o perímetro cefálico $(95,92 \%)$, torácico $(95,92 \%)$, altura $(97,96 \%)$ e peso $(93,88 \%)$ foram avaliados. O profissional mais reportado por realizar as consultas foi o médico $(95,92 \%)$. Quanto ao que foi orientado, observa-se que o AME e ganho de peso $(79,59 \%)$, o manejo da cólica intestinal $(77,55 \%)$ e regurgitações ou vômito após as mamadas $(59,18 \%)$ foram orientados em mais da metade das consultas. Quanto à puericultura, aponta-se que foram agendadas 45 consultas $(86,54 \%)$, sendo que ocorreram geralmente nos pri-
Tabela 4. Características da consulta realizada com o RN na unidade básica de saúde

\begin{tabular}{lcc}
\hline Características da consulta & Sim(\%) & Não(\%) \\
\hline Realizou a 1 ${ }^{\text {a }}$ consulta na UBS & $49(94,23)$ & $3(5,77)$ \\
Avaliado na consulta: & & \\
-Perímetro Cefálico & $47(95,92)$ & $2(4,08)$ \\
-Perímetro Torácico & $47(95,92)$ & $2(4,08)$ \\
-Altura & $48(97,96)$ & $12,04)$ \\
-Peso & $46(93,88)$ & $3(6,12)$ \\
-Temperatura/Frequência Cardíaca/Frequência & $25(51,02)$ & $24(48,98)$ \\
$\quad$ Respiratória & & \\
-Exame Físico & $36(73,47)$ & $13(26,53)$ \\
-Mamada & $29(59,18)$ & $20(40,82)$ \\
Profissional que consultou: & & \\
-Médico & $47(95,92)$ & $2(4,08)$ \\
-Enfermeiro & $2(4,08)$ & $47(95,92)$ \\
Orientação recebida: & & \\
-Manejo da cólica intestinal & $38(77,55)$ & $11(22,45)$ \\
-Aleitamento Materno Exclusivo (AME) e ganho & $39(79,59)$ & $10(20,41)$ \\
de peso & & \\
-Regurgitação ou vômito após mamadas & $29(59,18)$ & $20(40,82)$ \\
-Curativo/higiene do coto umbilical & $13(26,53)$ & $36(73,47)$ \\
-Eliminações intestinais/vesicais & $5(10,20)$ & $44(89,80)$ \\
-Cuidados com vestimenta & $3(6,12)$ & $46(93,88)$ \\
-Posição do bebê no berço & $4(8,16)$ & $45(91,94)$ \\
-Cuidados com a pele e prevenção de dermatites & $14(28,57)$ & $35(71,43)$ \\
-Como identificar sinais de perigo & $13(26,53)$ & $36(73,47)$ \\
-Manobras de desengasgo & $5(10,20)$ & $44(89,80)$ \\
Agendamento da puericultura: & $45(86,54)$ & $7(13,46)$ \\
-7 dias & $2(3,85)$ & $50(96,15)$ \\
-15 dias & $5(9,62)$ & $47(90,38)$ \\
-30 dias & $23(44,23)$ & $29(55,57)$ \\
-60 dias ou mais & $12(23,08)$ & $40(70,92)$ \\
-Não sabe & $3(5,57)$ & $49(94,23)$ \\
\hline
\end{tabular}

meiros 30 dias de vida da criança $(44,23 \%)$. Na tabela 5 encontram-se as intercorrências com o recém-nascido no primeiro mês de vida e as atitudes adotadas pelas mães para resolvê-las.

Dentre os RN, oito (15,38\%) foram atendidos por serviços de urgência, sendo que o serviço mais procurado foi a UPA $(62,5 \%)$. Os problemas mais recorrentes no primeiro mês foram as cólicas $(40,38 \%)$ e febre $(7,69 \%)$. Assim sendo, destaca-se que aproximadamente $40 \%$ ( $n=19)$ não tiveram nenhum problema de saúde nos primeiros 30 dias de vida. Com relação ao uso de chás, $25 \%$ das mães introduziram no primeiro mês de vida para alívio da cólica intestinal $(84,62 \%)$ e para acalmar/relaxar o RN (83,85\%). Na maioria das vezes foram os avós que recomendaram $(61,54 \%)$.

No que diz respeito à chupeta, um terço introduziu-a $(30,77 \%)$, tendo como principal motivo acalmar o RN (75\%). Percebe-se que poucas mães receberam orientações sobre as indicações e contraindicações do uso da chupeta (28,85\%), todavia, as que foram informadas receberam essa orientação do enfermeiro (73,33\%). 
Tabela 5. Problemas de saúde apresentados pelo RN no primeiro mês de vida: necessidade de atendimento, local acessado, tipo de problema, uso de chás para solucionar problemas de saúde e respectiva indicação

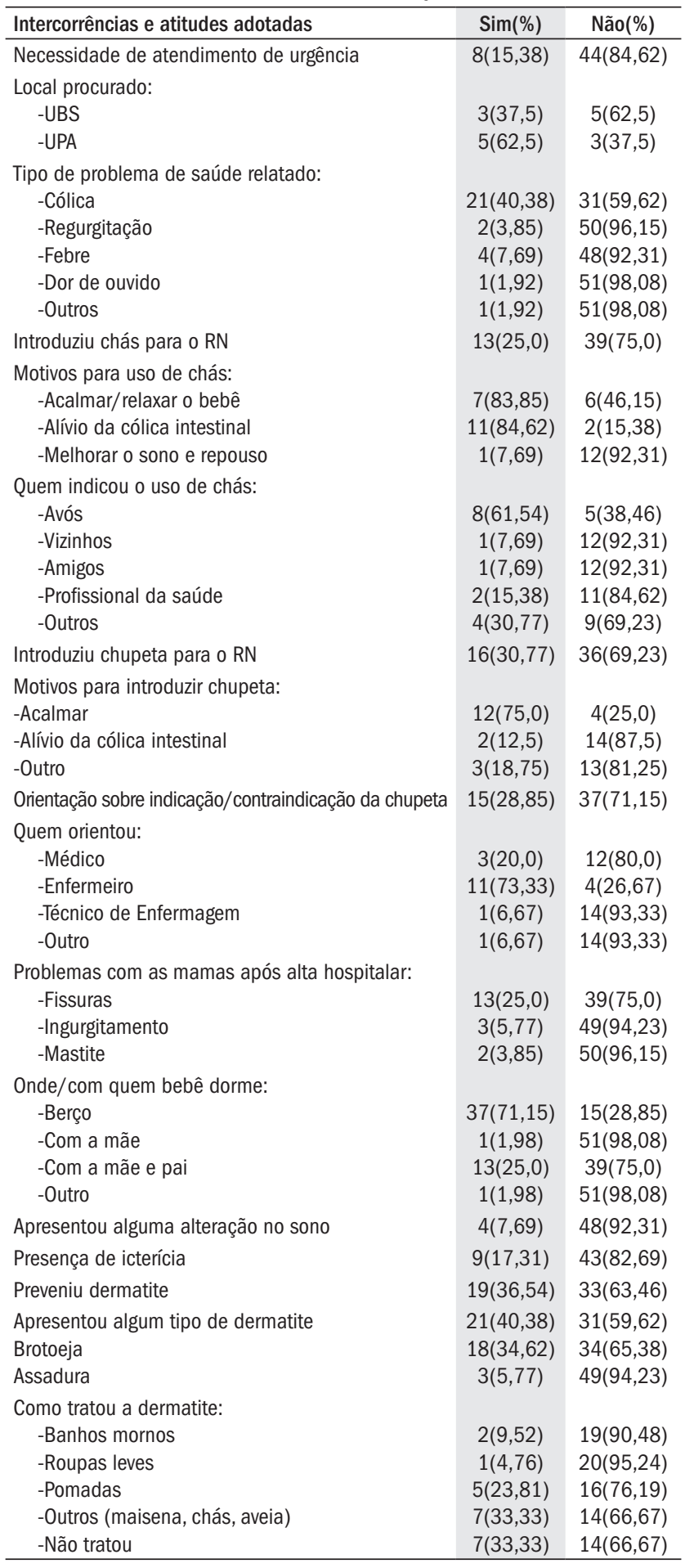

Após a alta hospitalar, 28,85\% ( $\mathrm{n}=15)$ das mulheres tiveram problemas com as mamas, dentre os mais frequentes mencionam-se as fissuras $(25 \%)$, o ingurgitamento $(5,77 \%)$, e a mastite $(3,85 \%)$. No que se re- fere ao sono e repouso do $\mathrm{RN}$, a maioria deles dorme no berço $(71,15 \%)$ e $7,69 \%$ tiveram alterações de sono. Ainda, 17,31\% dos RN foram avaliados e receberam o diagnóstico de icterícia, tratada com banho de sol, banho de luz e realizaram exames laboratoriais.

Com relação às dermatites, $36,54 \%$ das mães as preveniram, sendo o uso de pomadas o mais reportado. Todavia, 40,38\% dos RN apresentaram algum tipo de dermatite. Para tratamento, as principais práticas maternas realizadas foram adicionar ao banho: "pinga", maisena, permanganato de potássio e/ou chás de camomila e picão, além do uso de banha de porco para passar nas feridas $(33,33 \%)$.

\section{Discussão}

Evidencia-se que as práticas populares utilizadas no cuidado com as crianças são fruto da soma de saberes dos familiares, principalmente de pais e avós. Nesse sentido, percebe-se uma grande adesão às crendices populares no cuidado a criança, ${ }^{(8)}$ embora a ciência comprove que algumas delas não são benéficas. A perpetuação destas práticas também depende das condições sociais, escolaridade, faixa etária, bem como ao acesso a serviços de saúde de qualidade. Para tanto, é necessário a intervenção da equipe de saúde, atuando na educação em saúde, orientando, desmistificando tabus, mitos e crenças no intuito de diminuir os riscos à saúde da criança. ${ }^{(9)}$

Diante das orientações que as mães receberam dos profissionais de saúde, percebe-se que os achados desse estudo se assemelham aos encontrados em pesquisa realizada em maternidade do estado de São Paulo, com 30 puérperas, as quais receberam orientações dos enfermeiros da maternidade, para realizar cuidados com seu filho. As puérperas relataram que as orientações versaram sobre os cuidados com o coto umbilical, aleitamento materno até o sexto mês de vida, sobre a pega correta da mama pelo RN para amamentação efetiva, cuidados com as mamas, banho de sol, banho e higiene intima do $\mathrm{RN}$, assim como a troca de fraldas, além de que referiram sentir-se preparadas para realizarem os cuidados com o RN em casa. ${ }^{(10)}$

Quanto as visitas domiciliares à díade RN/puérpera na primeira semana pós-parto, obteve-se números insatisfatórios (19,23\%). Percebeu-se que não está 
sendo contemplado as orientações e determinações da linha guia mãe paranaense, no tocante as ações da primeira semana de vida integral. É de suma importância o seguimento do RN e sua família nas unidades de atenção primária, o qual deve-se ter início na primeira semana em que estão em casa após a alta hospitalar, pois este é um período crítico para adaptação da criança em casa, bem como dos pais à rotina de cuidar do RN no domicílio, além de ter influência positiva no AME. ${ }^{(6)}$ Ainda, estudo aponta que a realização da visita puerperal demonstrou ser significativa para estimar a probabilidade de ocorrer AME, sendo um fator para seu incremento. ${ }^{(11)}$

A primeira consulta do $\mathrm{RN}$ na atenção básica deve ocorrer ainda na primeira semana de vida, pois este momento se constitui em espaço de discussão de formas de estimulação que auxilia diretamente a família nas dificuldades/problemas inerentes à vida do RN. No presente estudo, nota-se que a consulta ocorreu até o décimo quinto dia de vida (75\%), corroborando com a literatura, em que se verifica que a consulta geralmente acontece entre o quinto e o décimo dia de vida $(42,8 \%){ }^{(12)}$

Ainda, quanto à primeira consulta desenvolvida na unidade de saúde, quase $90 \%$ das puérperas foram orientadas durante a avaliação da criança, sendo que as orientações foram comumente realizadas pelo médico. Dados estes, semelhantes a estudo desenvolvido com familiares de $\mathrm{RN}$, o qual promoveu estratégias de ensino em unidades de saúde, e verificou que as orientações ofertadas estavam presentes nos cuidados do RN, além da manutenção da influência familiar. ${ }^{(3)}$

Ademais, o acompanhamento constante do crescimento e desenvolvimento do RN por meio da puericultura e da observância de aspectos que abrangem a determinação social do processo saúde-adoecimento, como as condições de higiene, alimentação, da família, do ambiente, da comunidade, das condições socioeconômicas, dentre outras, são vitais para a qualidade de vida da criança e um futuro saudável. ${ }^{(13)}$

Com relação à amamentação, após a alta hospitalar quase 30\% das puérperas participantes desse estudo, tiveram problemas com as mamas, entre os quais, fissuras, ingurgitamento e mastite. Dados semelhantes foram encontrados em estudo descritivo e exploratório, realizado no Maranhão, o qual destaca que as nutrizes apresentaram dificuldades no manejo do alei- tamento materno, relacionadas à presença de fissuras e rachaduras nos mamilos, a pega inadequada e desconhecimento do valor nutricional do leite materno. ${ }^{(14)}$

Em pesquisa qualitativa realizada em unidades de saúde da família no município de Campina Grande - PB, observaram através de relatos das nutrizes que a causa de sofrimento e ansiedade mais apontada por elas foi o trauma mamilar, podendo influenciar no número e duração das mamadas, devido às dores que a mulher apresenta. ${ }^{(15)}$ Diante do exposto, os problemas mais recorrentes na hora da amamentação e/ou para não amamentar o RN estão relacionados à pega incorreta, sucção débil, baixa produção de leite, bico invertido, fissura e mastite, ${ }^{(16)}$ tal qual aos dados apresentados nessa pesquisa.

Neste estudo, a maioria das mães confirma conhecimento sobre o AME, destacando-se sua importância e vantagens, entendimento esse que converge a achados na literatura, como em estudo realizado com 297 gestantes, no terceiro trimestre de gestação, o qual avaliou o nível de conhecimento sobre aleitamento materno, identificando conhecimento regular. Ainda, tal conhecimento influencia tanto a intenção de amamentar quanto o tipo de alimentação do RN, sendo, portanto, um elemento a ser considerado no desenvolvimento de estratégias educativas voltadas para o aumento dos índices de aleitamento materno. ${ }^{(17)}$

No que se refere as práticas de cuidados materno ao RN, verifica-se na literatura dados muito semelhantes aos apresentados neste estudo, tendo como exemplo o uso de saberes populares em cuidados como o banho, para o tratamento de dermatites, com uso indiscriminado de pomadas, utilização de chás para alívio das cólicas, destacando-se a camomila e erva-doce. Percebendo-se dessa forma, a influência da cultura familiar nessas práticas. ${ }^{(9)}$

Em estudo realizado com 385 mães, em oito unidades de saúde no estado do Ceará, identificou-se que a maioria delas referiram não recorrer ao uso de chupeta para acalentar seus filhos, ${ }^{(18)}$ corroborando com os dados da presente pesquisa, em que mais da metade das mães não introduziram a chupeta para seus recém-nascidos.

Outro resultado observado no presente estudo, em acordo com a literatura, é em relação às intercorrências apresentadas pelo $\mathrm{RN}$, sendo os problemas mais recorrentes os respiratórios, diarreia e desidra- 
tação, candidíase oral e perineal e dermatite irritativa das fraldas, dentre outros. ${ }^{(13)}$ Sendo a cólica abdominal uma das principais intercorrências no primeiro mês de vida. ${ }^{(9)}$

Em estudo qualitativo desenvolvido com 12 gestantes, identificou-se que as crenças e mitos estão presentes no dia a dia, concluindo que as práticas populares de cuidados não é visto pelas mulheres como alguma coisa ruim, pois é algo cultural que seus familiares já vivenciaram, assim, encaram como um conhecimento relevante para o seu cotidiano e que lhes conferem experiências que podem ser muito úteis à saúde. De tal modo, o uso das práticas populares pode ser realizado, concomitantemente com o saber científico. ${ }^{(8)}$

Face ao exposto, percebeu-se que algumas práticas culturais são fortemente empregadas, principalmente pelos ascendentes familiares. Para tanto, o profissional de saúde deve trabalhar junto às mães e cuidadores de crianças, a fim de afastar práticas que possam colocar a vida do bebê em risco. Contudo, não pode se considerar o detentor único do saber, mas sim como possuidor de conhecimento científico, o qual, agregado ao saber popular, pode se somar para um melhor resultado em relação aos cuidados com o RN. (3) $^{(3)}$

Identifica-se como limitação do estudo o contato via telefônico para obtenção dos dados da pesquisa, ainda não muito usual no contexto brasileiro, que pode ter influenciado nas respostas quanto às práticas maternas. Assim, a continuidade de estudos sobre essa temática, que utilizem novas e diferentes metodologias, pode auxiliar numa compreensão mais ampla do fenômeno.

\section{Conclusão}

Embora as mães tivessem acesso aos profissionais de saúde para orientação, tanto na maternidade quanto na atenção básica, estas fizeram uso de cuidados baseados em saber popular, para solucionar problemas apresentados pelo recém-nascido no primeiro mês de vida. As intercorrências mais comuns encontradas foram as cólicas, febre e dermatites. Isto revela que, apesar de os profissionais ofertarem as orientações no pós-parto e nas consultas de puericultura, há a continuidade dos cuidados maternos baseados em crenças populares sobre o cuidado infantil, podendo ser influenciadas pelo contexto familiar e social a qual estão inseridas.

\section{Contribuições}

Minosso KC, Toso BRGO, Baggio MA e Ferrari RAP declaram que contribuíram com a concepção do estudo, análise e interpretação dos dados, redação do artigo, revisão crítica relevante do conteúdo intelectual e aprovação da versão final a ser publicada.

\section{Referências}

1. Bugs BM, Viera CS, Rodrigues RM, Conterno SF, Santos NT. Atividade educativa para mães de bebês prematuros como suporte para o cuidado. Rev RECOM. 2018;8:e2725.

2. Carvalho JM, Gaspar MF, Cardoso AM. Challenges of motherhood in the voice of primiparous mothers: initial difficulties. Invest Educ Enferm. 2017;35(3):285-94.

3. Gomes AL, Rocha CR, Henrique DM, Santos MA, Silva LR. Conhecimentos de familiares sobre os cuidados com recém-nascidos. Rev Rene. 2015;16(2):258-65.

4. Nunes RC, Freire MH, Willig MH, Mazza VA. Família e recém-nascido: diretrizes para uma nova prática de enfermagem. Enfermería (Montev). 2016;5(2):19-24.

5. Oliveira AK, Melo RA, Maciel LP, Tavares AK, Amando AR, Sena CR. Práticas e crenças populares associadas ao desmame precoce. Av Enferm. 2017; 35(3):303-12.

6. Lucena DB, Guedes AT, Cru TM, Santos NC, Collet N, Reichert AP. Primeira semana saúde integral do recém-nascido: ações de enfermeiros da estratégia saúde da família. Rev Gaúcha Enferm. 2018;39:e2017-0068.

7. Pinto Junior EP, Aquino R, Medina MG, Silva MGC. Efeito da estratégia saúde da família nas internações por condições sensíveis à atenção primária em menores de um ano na Bahia, Brasil. Cad Saúde Pública. 2018;34(2):e00133816.

8. Gomes LM, Melo MC. Práticas populares de cuidado: percepção de gestantes em uma Unidade de Saúde de Petrolina - PE. Espaç. saúde. 2015;16(3):53-63.

9. Brondani KJ, Ferrari RA, Cardelli AA, Tacla MT, Fançoso FG, Dalmas JC. Práticas maternas e uso de terapias alternativas no cuidado da criança. Cogitare Enferm. 2018;23(4):e54090.

10. Mercado NC, Souza GD, Silva MM, Anseloni MG. Cuidados e orientações de enfermagem às puérperas no alojamento conjunto. Rev Enferm UFPE. 2017;11(Supl.9):3508-15.

11. Carvalho MJ, Carvalho MF, Santos CR, Santos PT. Primeira visita domiciliar puerperal: uma estratégia protetora do aleitamento materno exclusivo. Rev Paul Pediatr. 2018;36(1):6673.

12. Moreira RF, Silva LG, Andrade HS. Assistência do enfermeiro ao recém-nascido na atenção primária de saúde. Cad. Esc. de Sau. 2018;17(2):61-78.

13. Zanardo GM, Andrade U, Zanardo GM, Menezes LP. Atuação do enfermeiro na consulta de puericultura: uma revisão narrativa da literatura. Rev Enferm. 2017;13(13):55-69.

14. Silva EC, Pereira ES, Santos WN, Silva RA, Lopes NC, Figueiredo TAM, et al. Puerpério e assistência de enfermagem: percepção das mulheres. Rev Enferm UFPE. 2017;11(Supl.7):2826-33.

15. Amaral U, Sales SS, Carvalho DP, Cruz GK, Azevedo IC, Ferreira-Junior MA. Fatores que influenciam na interrupção do aleitamento materno exclusivo em nutrizes. Rev Gaúcha Enferm. 2015; 36(Esp):127-34. 16. Toledo GM, Penna PS, Ribeiro LM. Duração e frequência de consultas médicas e sua influência no tempo de aleitamento materno em uma unidade básica de saúde. Rev Fac Ciênc Méd Sorocaba. 2018;20(1):23-8.

17. Suárez-Cotelo MD, Movilla-Fernández MJ, Pita-García P, Fernández Arias B, Novío S. Breastfeeding knowledge and relation to prevalence. Rev Esc Enferm USP. 2019;53:e03433.

18. Bezerra JC, Oliveira RK, Oliveira BS, Sousa SA, Melo FM, Joventino ES. Hábitos modernos relacionados à amamentação. Rev Baiana Enferm. 2017;31(4):e18247. 